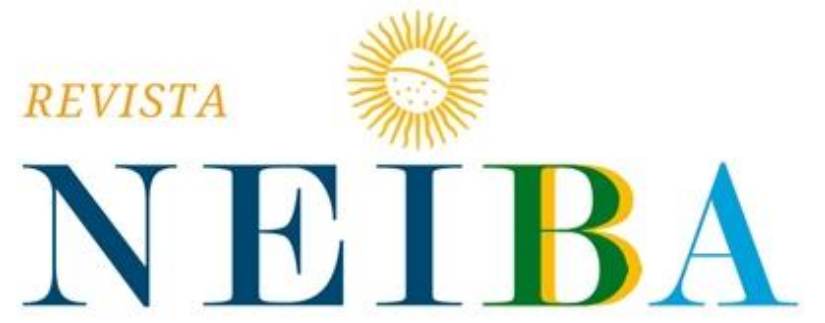

CADERNOS ARGENTINA-BRASIL
Volume 9, 2020, p. 01-29

DOI: 10.12957/neiba.2020.49982 | e49982 IISSN: 2317-3459

\title{
O AUTORITARISMO LATINO-AMERICANO: UMA DISCUSSÃO ACERCA DOS MECANISMOS DE LEGITIMAÇÃO E AS HERANÇAS AUTORITÁRIAS NO BRASIL (1964-1985) E NO CHILE (1973-1990)
}

THE LATIN-AMERICAN AUTHORITARIANISM: A DISCUSSION ABOUT LEGITIMATION MECHANISMS AND AUTHORITATIVE LEGACY IN BRAZIL (1964-1985) AND CHILE (1973-1990)

\section{Gastón Passi Livacic ${ }^{1}$}

José Carlos Martines Belieiro $\mathrm{Jr}^{2}$

${ }^{1}$ Universidade Federal de Santa Maria (UFSM), Rio Grande do Sul, RS, Brasil. E-mail: gaston pl86@hotmail.com ORCID: https://orcid.org/0000-0002-3609-6732

${ }^{2}$ Universidade Federal de Santa Maria (UFSM), Rio Grande do Sul, RS, Brasil. E-mail: jcmbjunior@yahoo.com.br ORCID: https://orcid.org/0000-0003-3507-6964

Recebido em: 08/04/2020 | Aceito em: 14/08/2020. 


\section{RESUMO}

O presente artigo tem por objetivo refletir acerca dos mecanismos de legitimação das novas formas de dominação autoritária na região que emergiram nos anos 60 e 70. Tais formas de governo emergem e se explicam por variáveis que respondem a uma legitimidade histórica, política e socioeconômica. Em tal sentido, tanto a emergência como o rumo de tais regimes se estabelecem desde uma dinâmica global, para tais efeitos, o seguinte trabalho analisará a estrutura fundacional das novas formas de dominação autoritária mediante a explicação teórico-analítica de legitimação mista do cientista político chileno Carlos Huneeus, posteriormente caracterizando cada uma das áreas de legitimação (histórica, política-institucional, econômica) entre os casos do Brasil e o Chile. A primeira parte do artigo pode se denominar como um estudo da memria política dos autoritarismos do Brasil e o Chile mediante uma perspectiva comparada, porém, ao mesmo tempo, se pretende comparar as heranças institucionais que emergem na consolidação de cada contexto autoritário por meio do que Carlos Huneeus chama de Presidencialismo semisoberano. Promove-se assim um debate acerca dos possíveis limites ao soberano poder que se instauram nos processos autoritários e sua relação com o retorno à democracia.

Palavras-chave: Legitimação em contextos autoritários; Brasil; Chile; Presidencialismo Semisoberano.

\section{ABSTRACT}

This article aims to reflect on the mechanisms for legitimizing the new forms of the authoritarian domination in the south-America in the sixties, seventies and eighties. Such forms of government emerge and are explained by variables that respond to the historical, political and socioeconomic legitimacy. In this sense, both the emergence ant the course of such regimes is established from a global dynamic, for such purposes, the following work will analyze the foundational structure of the new forms of authoritarian domination through the theoretical-analytical explanation of mixed legitimation and that of the political scientist Chilean Carlos Huneeus, later characterizing each of the areas of legitimation (historical, political-institutional, economic) between the cases of Brazil and Chile. The first part of the article can be called a study of the political memory 
of the authoritarianisms of Brazil and Chile through a comparative perspective, but at the same time, it is intended to compare the institutional inheritances that emerge in the consolidation of each authoritarian context through what Carlos Huneeus calls it semi-sovereign presidentialism. This promotes a debate about the possible limits to the sovereign power that are installed in authoritarian processes and their relationship with the return to democracy.

Keywords: Legitimation in Authoritarian contexts; Brazil; Chile; Semi-Sovereign Presidentialism.

\section{INTRODUÇÃO}

O presente artigo tem por objetivo analisar suscintamente os regimes autoritários chileno (1973-1990) e brasileiro (1964-1985) por meio de algum dos eixos teóricos mais relevantes do cientista social chileno Carlos Huneeus. No mundo atual, como se sabe, há um forte e intenso debate no campo específico da ciência política bem como as demais ciências sociais, sobre as tensões e conflitos que cercam as democracias contemporâneas, e a América do Sul não está fora alcance dessas questões. Tais limites e tensões que atravessam as democracias latino-americanas podem ser observados por meio de diversas óticas e correntes teóricas e de análise política.

No Brasil atual, são abundantes as ameaças e provocações estimuladas por iniciativa da Presidência da República contra as instituições do Poder Legislativo, como o Congresso Nacional e mesmo contra o Poder Judiciário, representado por sua instância máxima, o Supremo Tribunal Federal -STF. De outro lado, a militarização crescente das pastas ministeriais no governo de Jair Bolsonaro pode representar uma degradação da democracia como a forma relacional predominante. No caso chileno, os limites da democracia emanam da articulação de uma nova espécie de configuração social (conhecido como o Outubro de 2019) reclamando por maior espaço de participação política, e ampliação do leque de direitos econômicos e sociais que antes foram negados.

Neste artigo, propomos discutir os regimes autoritários de Brasil e Chile a partir de uma tripla perspectiva, ou seja, primeiramente, mediante uma ótica que se poderia classificar como um enfoque de estudo de política da memoria, em segundo plano, 
desde uma perspectiva da política comparada, onde se procura analisar as correspondências estruturais e as peculiaridades na consolidação de cada processo político no período autoritário, e, finalmente, comparar as possíveis heranças institucionais que podem representar o "legado" tais formas de governo e a sua relação com os limites atuais das democracias recentes de Brasil e Chile.

De acordo com os trabalhos de Carlos Huneuus, todos os sistemas políticos, incluído os regimes autoritários, como o brasileiro e o chileno, emanam de uma justificação histórica, ao mesmo tempo, procuram mecanismos de legitimação institucional, política, econômica e social. Para os efeitos de nosso argumento, como fonte de primeira categoria analítica, se caracterizaram as experiências de cada país em cada uma das dimensões de legitimidade apontada por Huneeus, em segunda instância, discutindo os principais contornos com livros ou artigos de reconhecidos académicos que abordem o período circunscrito para, posteriormente, as possíveis correspondências como as particularidades de cada processo político-institucional.

Segundo a teoria escolhida para este trabalho, os regimes autoritários nos casos de Brasil e Chile procuram estratégias de justificação em diversos aspectos de cada sistema político, em consequência, o arcabouço teórico utilizado por Carlos Huneeus possibilita pensar tanto a emergência de tais formas de dominação, permitindo recortes pontuais do período, assim como uma interpretação global das suas transformações, em efeito, não atomizando as estratégias de legitimação em partes isoladas sem uma conexão sistêmica. Os indicadores de comparação global, projetados como as formas de legitimação em suas diversas formas (histórica/tradicional, legal e socioeconômica), permite confrontar os casos aludidos em áreas específicas, entretanto, e, desde uma dimensão analítica, seriam possíveis avaliar as correspondências entre os casos assim como as características próprias de cada processo decisório, ao mesmo tempo, observando os limites ou heranças institucionais plasmada nas relações de poder de cada sistema político.

Afinal, o que são as heranças institucionais? Para o autor, refere-se aos limites ao poder soberano, ou seja, ao poder das maiorias herdados ou legados das transformações e posterior consolidação dos autoritarismos apontados como objeto de 
trabalho no presente artigo. Uma das teses fundamentais para Carlos Huneeus esgrime que no processo autoritário chileno se plasma uma democracia protegida através do que ele denomina de presidencialismo semisoberano, entendido como os limites ao poder de decisão do Presidente da República. Essa tese é replicável ao caso brasileiro? De ser afirmativa essa correlação, quais seriam os pontos de encontro /desencontro com o caso chileno? Que implicâncias produzem?

\section{INSTÂNCIAS DE MEDIAÇÃO E/OU LEGITIMAÇÃO DOS DENOMINADOS NOVOS AUTORITARISMOS}

Um dos objetivos fundamentais do trabalho teórico de Carlos Huneeus é procurar entender as principais áreas de conflito que configuram a emergência dos autoritarismos latino-americanos nos anos 60 e 70, os chamados novos autoritarismos indicados por David Collier. De outro lado, também se preocupa com as mudanças que se geraram internamente, os blocos de poder. Os blocos de poder servem como forma de vislumbrar exatamente que tipo de poder se consolida no regime autoritário chileno. Em tal sentido, o problema da institucionalização do regime ${ }^{3}$ é um dos eixos fundamentais desta perspectiva teórica.

De tal maneira, a prioridade interpretativa do autor não é só entender a emergência dos autoritarismos nos países da região, mas também como se institucionalizam, os novos conflitos que apareceram na cena política. A partir da teoria escolhida, o que se pretender abordar é que tipo de poder se consolida em cada um dos dois autoritarismos selecionados em uma perspectiva de política comparada. Entre as múltiplas áreas de tensão que puderam ter os autoritarismos selecionados, o cientista social chileno Carlos Huneeus menciona que: "não só o problema da desnacionalização pode provocar tensões e conflitos entre grupos, a elite civil e os militares, senão havendo outros mais, tais como o problema da repressão, política

\footnotetext{
${ }^{3}$ Carlos Huneeus: por instituições entendemos normas, mecanismos e estruturas destinadas a regular o conflito, os procedimentos usados para reduzir ou ampliar as capacidades inclusivas ou excludentes do Estado e, no fundamental, resolver oportuna e adequadamente o problema da sucessão, ou seja, a continuidade da dominação autoritária pelas mesmas elites, e, eventualmente, pelos mesmos indivíduos, e com mesmos objetivos e prioridades, políticas e econômicas (Huneeus, 1981, p. 104).
} 
exterior, a questão do estabelecimento de mecanismos de cooptação, participação, etc.". (Huneeus, 1981, p. 105)

Diante de tal dilema, Huneeus considera que a melhor forma de entender a dinâmica política que enfrentam tais autoritarismos versa sobre a compressão dos variados métodos de regulação do conflito, o que ele cataloga como a dinâmica política que se exerce dentro das relações de poder. Negando, dessa forma, as propostas que postulavam o caráter unidimensional nos tipos de conflitos que enfrentaram tais autoritarismos. Isso quer dizer que o regime não pode se consolidar só na coalizão governante-legitimação para dentro-. Por outro lado, é necessário também compreender a - legitimação para fora -, tais argumentos se inserem em que nenhum regime político é indiferente à opinião das maiorias.

Carlos Huneeus menciona que nos regimes autoritários entrelaçam as seguintes formas de legitimidade:

A legitimidade do sistema político pode ter três fontes: histórica ou tradicional, quando a ordem política se apoia no desenvolvimento histórico do país, próximo ou distante, legal ou constitucional, quando se apoia em um ordenamento jurídico que o próprio regime põe em vigor um procedimento formalmente determinado; e em terceiro lugar, a legitimidade para adiante, e rendimento, mediante políticas que pretendem satisfazer as necessidades mais urgentes da cidadania, especial e socioeconômica ${ }^{4}$. (Huneeus, 1986, p. 118).

Portanto, Carlos Huneeus, sustenta que os regimes autoritários procuram cimentar uma senda de legitimação mista. Com efeito, a execução de políticas sobre tais eixos /dimensões temáticas, em termos globais, ajudaram à consolidação de tais regimes autoritários. Cabe destacar, que as formas de legitimação devem ser compreendidas em contextos autoritários. Como consequência, esses propósitos não satisfazem os mesmos requisitos que em um regime democrático. Desse modo, as formas de legitimação, em contextos autoritários, são entendidas como ferramentas políticas que intentam justificar, ao mesmo tempo, construir um tipo de projeto país, dessa ótica, o objetivo primordial do presente trabalho é enxergar que tipos de projetos se consolidaram em cada um dos casos escolhidos assim como suas possíveis repercussões para a democracias de cada nação.

\footnotetext{
${ }^{4} \mathrm{O}$ conceito de legitimação para atrás e para adiante tem sido inspirado em Guiseppe Di Palma: "Founding Coalitions in Southern Europe, Legitimacyand Hegemony, Govermentand Oppositions, 15/1980, p. 162-189.
} 
A discussão das diferentes formas de legitimação se caracterizará mediante uma comparação entre as experiências autoritárias do Brasil e do Chile, desse modo, se pretende abrir um tipo de debate geral abordando as divergências ou semelhanças tanto na emergência como na consolidação de tais regimes, incluindo também interrogantes tais como: as prioridades do processo de consolidação são iguais? Ambos os países, mediante a consolidação, tentam consolidar uma legitimação futura "eliminando institucionalmente os vícios do passado"? Ou seja, é possível achar nos dois objetos de estudos limites ou restrições permanentes ao poder soberano configurado para regular seu exercício no retorno à democracia? Entre outras perguntas.

A hipótese que orienta o artigo trata os regimes autoritários em observação como fenômenos de uma ampla transformação cuja consolidação no contexto autoritário promove "mecanismos de justificação" além da mera contingência, ou seja, em limites ao poder da maioria. Para tais efeitos, se analisaram a consolidação de cada autoritarismo, suas principais preocupações assim como a arquitetura construída no tocante aos indicadores esboçados. Finalmente, comparando os graus de projeção e profundidade ao poder soberano para cada um dos casos, os seus possíveis laços assim como suas peculiaridades e continuidades ainda presentes na conjuntura de cada momento político.

\section{ESTRATÉGIAS DE LEGITIMAÇÃO HISTÓRICA}

Para nosso autor, a legitimidade histórica ou tradicional, refere-se aos elementos que justificam, perante aos olhos dos atores com poder, a intervenção militar nos processos decisórios. Essa intervenção, analisada desde a ótica da legitimação histórica ou tradicional, é tratada por meio de diversos mecanismos, por exemplo, observando as principais áreas de conflito no período precedente, a configuração do poder presidencial e o alcance deste, o modelo de organização socioeconómico assim como as implicâncias da polarização desembocadas nas respetivas respostas autoritárias.

Os graus de polarização política assim como a sensação de ameaça para as elites locais configuram diferentes intensidades ao momento tanto de justificar a emergência autoritária assim como no processo de consolidação do modelo político no período autoritário. Assim de igual forma, na configuração da arquitetura institucional em longo 
prazo do autoritarismo, compreendida como os mecanismos de defesa às mudanças sociais e econômicas demandas no contexto. Estipula-se que ameaça as relações de poder político, económico e sociais para o caso chileno evocam uma resposta muito mais radical que para o caso brasileiro, em consequência, o desenho da engenheira para o futuro adquire numa perspectiva muito mais global e potente.

O modelo que se constrói no caso chileno deve ser considerado como revolucionário, portanto, esboça uma ruptura total com o período precedente no processo autoritário. Para o caso brasileiro, se acredita que dita mudança é apontada a zonas consideradas críticas enquanto o objetivo era "corrigir" ou "restaurar" certos elementos considerados como anômalos. Porém, a restruturação do caso brasileiro não exclui a possibilidade de consolidar e projetar mecanismos de controle ao poder soberano fora do contexto autoritário, por tais motivos, as seguintes reflexões procuram responder as interrogações apontadas no percurso do artigo, avaliar as principais mudanças e sua projeção de longo prazo, comparar a profundidade da modificação do processo decisório, e as áreas afetadas, entre outras questões.

No plano global, e projetando a justificação numa perspectiva comparada, no caso chileno, é possível observar a concentração do poder político na figura presidencial de Augusto Pinochet por causa de uma sociedade altamente polarizada, entretanto, no caso brasileiro, a sucessão de Presidentes no regime militar (Castelo Branco, Costa e Silva, Médici, Geisel e Figueiredo) se invoca como um mecanismo de regulação dos conflitos evitando assim a concentração do poder somente em um referente, ou seja, alude uma necessidade, histórica e institucional, de pôr limites sobre o poder presidencial.

Quanto a matriz econômica, em termos da teoria do autoritarismo-burocrático do politólogo argentino Guillermo O’Donnell, uma das perspectivas dominantes sobre as mudanças de regime na América do Sul, aponta o caso brasileiro de fundacional, pois consegue se aprofundar (continuar industrializando-se), por outra parte, o caso chileno não seria fatível como consequência do reduzido mercado interno assim como da alta ameaça inicial. Porém, isso não significa que o caso chileno tenha ficado estagnado somente na repressão, ao contrário, a transformação da economia chilena pode ser 
considerada como revolucionária enquanto se estipulou como uma rearticulação total em relação ao passado recente, tornando o mercado como o mediador entre a cidadania/consumidores e ofertantes relegando assim o Estado num papel de subsidiário. Entretanto, o caso brasileiro pode ser considerado como uma reestruturação de certas áreas ou zonas da engrenagem política considerada anômala ou disfuncional pelos atores com poder, ou seja, é a rearticulação da ordem, considerada alterada no período precedente. Por tais efeitos, aprofundar o rumo da industrialização se transforma na prioridade mais importante, desse modo, eliminar a polarização nos circuitos do poder, evitar a margem de manobra sobre o modelo de industrialismo para o Presidente da República, tanto na perspectiva geral como na possibilidade de transitar para uma polarização social "efeito contagio", assim como erradicar da arena políticas os grupos considerados subversivos.

No caso chileno, a experiência democrática anterior ao golpe combinado com um pluralismo altamente politizado se extrapola em conformidade dessa ampla gama de atores políticos e ideologias em tensão para todo o sistema político do país sulamericano. O cientista político chileno, Arturo Valenzuela (1989), sustenta a tese de um caminho transversalmente 'revolucionário' para explicar o golpe de Estado chileno de 1973. Os riscos se manifestaram em uma concatenação de fatores: hipermobilização, altos índices de sindicalização, polarização da sociedade, confisco de empresas privadas através da utilização de resquícios legais, entre outras. Todos esses elementos englobados, em última instância, colocaram em tensão permanente uma forma de dominação política, ao mesmo tempo, o modelo capitalista vigente no Chile.

Sendo assim, e tendo em vista dos elementos ponderados, "o propósito foi reconstruir as bases relacionais entre economia, sociedade e Estado, em que a finalidade era criar uma ordem socioeconômica suficientemente sólida capaz de resistir às alternativas de governo e regimes" (Huneeus, 1986, p. 125). As mudanças no sistema de previdência social, educação, saúde, entre outras, orientam o alvo principal da nova ordem construída, ou seja, uma arquitetura cujo pilar fundamental procura a despolitização dos sujeitos sociais em vista que as antigas formas de organização e 
institucionalização, as que terminaram por politizar a sociedades além dos limites permitidos.

Perante o quadro originário da crise, a imposição do Estado Subsidiário, instaurado na constituição de $1980^{5}$, foi desenhada e projetada para eliminar todas as áreas consideradas promotoras da politização. Por conseguinte, a delegação de funções estatais ao setor privado descansa nesta dupla forma de legitimação, para trás - para adiante.

No caso brasileiro, as Forças Armadas conseguiram sua intervenção no horizonte de se autoproclamar como as corretoras do processo político derivada da endógena instabilidade política, sustentadas em todas as tentativas de golpes de Estado durante a fase democrática de 1945-1964, em decorrência, principalmente, dos programas de governo das lideranças populistas. Nesse sentido, existe uma imbricação, em termos políticos, de duas crises, por um lado, de correção às imperfeições ao método competitivo, em consonância com o anterior, a instauração de sucessivas eleições presidenciais dentro do regime autoritário brasileiro: em parte como resposta à instabilidade, de igual forma, como mecanismo de contenção à possibilidade da ascensão ao poder de figuras políticas como Getúlio Vargas e sucessores, atores que pudessem politizar de fora dos parâmetros aceitáveis ao corpo social.

No caso chileno houve uma politização global do sistema político sendo possível observar uma polarização política extrema, por outra parte, no caso brasileiro, a emergência se configura a partir do alto poder que constituía a máxima magistratura do país, consequentemente, do risco de se perpetuar no poder assim como da possibilidade de politizar os sujeitos sociais desde o cume do sistema, em concomitância também, de dominar exclusivamente o tipo de industrialização. No Brasil, a ameaça origina-se de acordo com Guillermo O'Donnell: das ações de personagens como Brizola e Gourlart, que estavam dispostos a mobilizar recursos do Estado para radicalizar o setor popular (O’Donnell, 2013, p. 107). No Chile, entretanto,

\footnotetext{
${ }^{5}$ Em termos gerais, o Estado Subsidiário tem por fundamento relegar todos os aspectos econômicos das sociedades aos privados e suas funções vêm-se reduzidas somente quando os privados estimam não convenientes investir em uma determinada área, portanto, suas funções se relegam ao de fiscalizador de tais aspectos econômicos e ao mesmo tempo fornecer serviços essências em espaços não atendidos pelos privados, por exemplo, saúde e educação.
} 
emerge da polarização total do sistema competitivo, sendo assim a falta de consenso demonstrada no conjunto da sociedade, configurando um cenário de contramobilização fora do alcance para a hegemonia política.

O sistema de competição eleitoral também pode ser um fenômeno importante para entender os diferentes rumos de cada sistema político. Nesse sentido, o caso chileno mediante a desestatização da economia procura eliminar o Estado empresário e de bem-estar enquanto a dinâmica política dessa organização social terminou por polarizar a sociedade em conjunto de níveis irremediáveis, em consequência, a desestatização do Estado deve ser entendida como um projeto de ordem política, económica e social de inspiração autoritária. No caso brasileiro, o regime continua com o processo de industrialização, entretanto, o risco da polarização foi menor que o caso chileno, nesse aspecto, o risco sobre o tipo de industrialização se transforma na principal disputa da cena política.

Segundo René Armand Dreifuss, as alternativas em discórdia estavam representadas por o estatismo nacional-reformista versus o capital oligopolista multinacional associado. Essa disputa foi escalando em tensão chegando-se debater quem devia dominar a industrialização e o alcance desse domínio. Para o partido comunista e os intelectuais nacionalistas "havia duas burguesias, uma considerada de entreguista, diretamente ligada ao capital transnacional, e outra nacionalista, oposta aos interesses estrangeiros" (Dreifuss, 1981, p. 25).

Para os ideólogos do Golpe do Estado no Brasil as ameaças se encontravam nos governos nacionais - populistas, tipo de dominação "que procurava estabelecer um esquema de limitada mobilização política nacional de massas urbanas, baseado em uma estrutura sindical controlada pelo Estado e no apoio institucional do PSD e O PTB" (Dreifuss, 1981, p. 27). Ou seja, para René Armand Dreifuss o medo dos grupos contrários à mobilização social e o nacionalismo no projeto de industrialização brasileiro versavam sobre a possibilidade do executivo, por intermédio das lideranças populistas, se transformarem em uma instância institucional com maior independência, relativizando o acordo com empresas multinacionais, capitais associados, Forças Armadas como instituição, entre outros, sobre o rumo da industrialização brasileira. 
Por tais motivos, se the denomina a essência econômica do autoritarismo brasileiro como uma modernização-conservadora, entretanto, seu escopo principal não era eliminar o desenvolvimento alcançado, ao contrário, seu proposito estava englobado em articular limites ao processo de industrialização com medidas antipopulares e antipopulistas, assegurando o processo de acumulação excluindo as classes trabalhadoras do espaço político e da distribuição da riqueza do trabalho.

\title{
LEGITIMAÇÃO LEGAL
}

Para o cientista político, Carlos Huneeus, em relação à dimensão legal dos autoritarismos em observação: "se se admite que a premissa de que estes regimes autoritários buscam se consolidar para redefinir as relações entre Estado e sociedade, é necessário, portanto, indagar quais são essas múltiplas estruturas, mecanismos e processos que o permitem ou o explicam" (Huneeus, 1986, p. 106). Para tais efeitos, o autor se baseia no estudo das eleições não-competitivas que, entre as funções analíticas, permite dimensionar as relações entre o governo e a oposição, mas, ao mesmo tempo, permite esclarecer diversos tipos de desafios conflituosos com os quais deveram lidar estes tipos de regimes. Sendo assim, se exploraram as funções/estratégias que cumprem essas eleições no périplo fundacional cujo escopo fundamental emana da perspectiva de que tipo de poder se consolida mediante a vertente legal.

Antes de começar analisar as diferenças entre as funções e as experiências autoritárias de Chile e do Brasil é necessário definir os tipos de eleições nos autoritarismos:

\begin{abstract}
As eleições não-competitivas são aquelas nas quais não existe nenhuma das condições encontradas nas eleições competitivas: não há opções de candidatos, o eleitor carece de liberdade, e estas eleições não têm consequências no governo, porque está apoiada no monopólio do partido único. As eleições semi-competitivas são aquelas nas quais existe uma competência limitada entre candidatos (se tolera uma semi-oposicao ou uma oposição legal), o votante pode escolher entre eles, embora o monopólio dos meios de comunicação de massas por parte do governo, mas, se podem eleger representantes em assembleias ou no parlamento, embora sem conseguir mudar a composição do governo. (Huneeus, 1986, p. 108-109).
\end{abstract}

Nessa linha analítica, surgem as seguintes questões, tais como: quando, como e porque utilizar o método de eleições em circunstâncias autoritárias? Neste caso, nas 
eleições semi-competitivas, segundo Huneeus, podem ser instrumentais de acordo com a experiência que demonstram "os Estados africanos os que evidenciaram que as eleições eram eficazes mecanismos para criar e ampliar a legitimidade do regime e serviam para mobilizar a população" (Huneeus, 1986, p. 108). Principalmente, quando tais regimes não conseguem satisfazer as necessidades econômicas de sua base de apoio, este mecanismo se transforma em uma garantia para manter tais aliados. Com efeito, se recorre nestes mecanismos quando o governo não tem êxitos econômicos [...]Estas eleições podem ser utilizadas para reconstituir ou consolidar a coalização governante, neutralizando à semioposição e obrigando-a a se aderir incondicionalmente ao regime (Huneeus, 1986, p. 108)

Essas são algumas das funções que podem satisfazer as eleições em regimes autoritários, apesar de não existir uma teoria geral das eleições não competitivas nem semi-competitivas que demonstrem as estratégias, funções e implicações. Estas eleições ocorreram nos regimes autoritários brasileiro e chileno, evidenciando assim a negação à tese de que o único vínculo entre a aliança golpista e o resto da sociedade se fez via temáticas econômicas. Por exemplo, em países com uma longa tradição democrática, "a convocatória pode ser apresentada como retomar algo próprio da tradição política do país, uma vez que a fase teve que ceder ante a necessidade de fundamentar o regime sobre elementos positivos e não a mera crítica à democracia" (Huneeus, 1986, p. 109).

Tendo presente que as eleições representam um leque amplo de possibilidades, e em vista de algumas considerações apresentadas, os mecanismos institucionais do caso brasileiro responderam em função da estratégia de se projetar como a antinomia do processo demagógico-populista, enquanto as eleições pontais no caso chileno evidenciam uma recusa mais importante aos atores que lideravam o processo democrático devido ao esporádico destas no período autoritário, mas não por isso, deixou-se de utilizá-las. Em concomitância, outro dos tópicos que pressupõe uma área de legitimação de um regime autoritário refere-se à condução de um líder em vista da insuficiência de legitimidade que per se geram as instituições militares. Essa zona de conflito deriva-se da linha vertical de mandado assim como das disputas entre os 
chamados a ser as lideranças do processo autoritário, sendo assim, o politólogo chileno argumenta que:

\begin{abstract}
Uma direção colegiada expressada em uma junta de governo pode ser ineficaz para resolver problemas econômicos e sociais que afetam ao país. Daí que os regimes autoritários mostrem uma tendência de mudança de uma dominação colegiada expressada em uma Junta de Governo composta por comandantes em Chefe das FF.AA. para uma chefia de Estado unipessoal e altamente pessoalizada (Huneeus, 1986, p. 130).
\end{abstract}

A institucionalização dos dois casos sustenta a tese de Huneeus, não obstante, com graus de institucionalidade distintos expressados de acordo com as prioridades políticas em relação à leitura histórica de cada caso. Do lado brasileiro, a breve estadia da Junta Militar sustenta as afirmações precedentes, mas entre os seus objetivos: 'prometia-se restaurar a legalidade 'e reforçar as instituições democráticas ameaçadas'. Diante de tal delineação institucional, rapidamente se abre a vaga para o Presidente da República no Ato Institucional №1:

O Ato continha uma primeira tentativa de institucionalizar o mecanismo de transferência do Poder Executivo. O primeiro Colégio Eleitoral encarregado de escolher indiretamente o Presidente do Brasil era composto por 326 deputados e 62 senadores de um Congresso cuidadosamente depurado. 0 General Humberto de Alencar Castelo Branco recebeu um total de 361 votos e foi empossado como presidente no dia 15 de abril de 1964, substituindo a Junta Militar que governara na condição de Alto Comando Revolucionário durante o primeiro mês do Estado de Segurança Nacional" (Alves, 2005, p. 55).

Vê-se, assim, que as eleições não-competitivas podem servir como instrumentos para legitimar politicamente ao chefe de Estado, ao contrário, no caso chileno, este não apresentou eleições periódicas nesta matéria, como ocorreu no caso brasileiro onde se permitiu a existência de dois partidos políticos formais, um governista como foi a Arena (Aliança Renovadora Nacional) e outro de oposição ao regime, como foi o MDB. No sistema bipartidário brasileiro, manteve-se uma participação controlada, porém dinâmica, como se observou da experiência do bipartidarismo, já que as eleições legislativas em todos os níveis, municipal, estadual e federal, foram mantidas nos anos 1966-1982.

No caso chileno, o General Pinochet, entre outras formas, também procurou se legitimar mediante este tipo de eleições. A primeira das eleições no caso chileno teve relação com o plebiscito de 1978 contra uma resolução da ONU, cuja gênese se 
remonta às críticas internacionais ao regime por causa de sua atuação em matéria de direitos humanos. Contudo, a manifesta personalização do plebiscito configurou a rápida recusa do Comandante da Força Aera Gustavo Leigh: "este já se encontrava em uma posição antagônica a Pinochet devido ao custo social da política econômica e personalização do poder". (Huneeus, 1986, p. 131). Simultaneamente, o referendum da Constituição em 1980 também favoreceu a figura de Pinochet, o qual por intermédio de sua aprovação conseguiu se garantir minimamente 16 anos no poder ${ }^{6}$.

Assim, é possível perceber que existe uma institucionalidade que se cria e que, apesar de as diferenças, são substanciais para a consolidação dos novos regimes autoritários. Carlos Huneuus (1986) argumenta que:

\begin{abstract}
O regime autoritário gira em boa medida em torno ao chefe de Estado, que pode concentrar em seu poder a chefia das FF.AA., e, eventualmente, a chefatura do governo, na qual pode delegar num leal colaborador, militar ou civil. A maior grau de consolidação do regime maior probabilidade de que o governo adquira uma independência relativa do chefe de Estado, diferenciando-se as funções de entre política de Estado e Governo. Isso Ihe permite ao chefe de Estado cumprir uma função arbitral nos conflitos entre grupos e elites que representadas no governo, sem ter que se desgastar numa atividade administrativa. (Huneeus, 1986, p. 130-131).
\end{abstract}

O autoritarismo institucional brasileiro, desde os seus primórdios, definiu o processo fundacional com normas e regras que definiriam o percurso por meio do vigor de tais procedimentos. A leitura geral configurou-se na perspectiva de procurar certa legitimidade em vista das seguintes garantias, entre alguns fundamentos: mobilização de apoio, coesão dos grupos, como também na possibilidade de uma nova eleição presidencial, controlando-se assim as disputas internas pelo poder. Além disso, controlando a oposição neste enquadramento institucional e, em cenários com resultados negativos, estas serviriam como uma espécie de termômetro social, entretanto, se aplicaria uma série de medidas para um controle mais rigoroso: aplicação da força, processos de cassação ou mudanças nas regras eleitorais para evitar o crescimento da oposição político-partidária.

Um exemplo daquilo foram alguns dos novos eixos de ação no Ato Constitucional Número 2, de 1965, quando se extinguiram todos os partidos políticos

\footnotetext{
${ }^{6}$ Na constituição de 1980, ao mesmo tempo, de se aprovar a Carta Magna, se incluía também a possibilidade de Pinochet ficar mais oito anos no poder no caso da obtenção de uma vitória no plebiscito de 1988.
} 
existentes, em vista dos resultados para as eleições de governadores (prejudiciais para o autoritarismo em curso). Tais medidas orientaram-se em desarticular a oposição, principalmente, para evitar seus vestígios passados ademais de um processo competitivo instrumental á coalização no poder, portanto, assimétrico para outros grupos da sociedade:

Não Ihe interessava ao Estado de Segurança Nacional montar um sistema unipartidário. Visando na sua própria legitimação, o Estado queria um partido de 'oposição responsável', ao qual caberia oferecer 'crítica construtiva' ao governo [...] Os vários partidos de oposição associaram-se para formar o Movimento Democrático Brasileiro (MDB). O partido de apoio ao governo foi denominado Aliança Renovadora Nacional (ARENA). (Alves, 2005, p. 94)

O quadro geral do processo institucional brasileiro, tanto nos Atos Institucionais assim como na Constituição de 1967, se moldaram de acordo com as necessidades da coalização governante, portanto, a mudança de normas se estrutura "da necessidade de consolidar um controle em todos os níveis de poder político [...] considerando imperiosa a adoção de medidas que não permitam que se frustrem os objetivos superiores da Revolução" (Alves, 2005, p. 55). Entre eles, destacaram-se várias medidas, tais como as eleições presidenciais indiretas, mudanças de quase todas as regras no Congresso, mudanças nas regras no processo de eleições, entre outras medidas restritivas.

As análises apresentadas não tiveram por escopo desenvolver um quadro minucioso das eleições não-competitivas, entretanto, o eixo nodal da presente seção teve por objetivo demonstrar de modo geral, que a consolidação destes regimes não se baseou exclusivamente em mediações de caráter econômico. Concomitantemente, tentou-se ilustrar uma comparação à luz da leitura das elites dominantes em relação ao processo de legitimação legal utilizada e os objetivos de cada sistema, para com isso, visando compreender a incidência histórica "na instrumentalização" da dimensão legal em contextos autoritários, assim como na perspectiva da consolidação do regimes, tentando entender o encadeamento dessa lógica "legitimidade para adiante".

Por outro lado, manifestamente, tais eleições não podem ser interpretadas com a mesma lupa que em um contexto democrático, e mesmo considerando as lógicas restrições em tais cenários, estas podem servir para a negação do veículo da mobilização, adesão e resolução de conflitos em uma perspectiva unidimensional. No 
caso chileno, a revolução se sustenta na Constituição de 1980, procurando estabelecer uma aliança de poder, mobilizar apoio e, fundamentalmente, proteger as transformações realizadas além do espaço temporal autoritário mediante os chamados enclaves autoritários ${ }^{7}$, por outra parte, as Forças Armadas brasileiras se posicionam no jogo político como corretoras dos erros pretéritos, em tal aspecto, a nova ordem em disposição se configurou fundamentalmente para, além de erradicar as forças populista-reformistas da cena política, contornar a margem de ação do modelo de desenvolvimento entre um reduzido grupo de atores, garantido também, uma discussão permanente sobre as definições políticas e económicas do modelo.

\section{LEGITIMAÇÃO ECONÔMICA}

A teoria do Estado burocrático-autoritário, do politólogo argentino Guillermo O’Donnell, é uma das obras mais reconhecidas na região acerca de relação entre a estrutura socioeconómica e mudanças de regimes políticos. Esse trânsito, fundamentalmente, é explicado a partir das pressões na internacionalização da economia de países considerados periféricos. O escopo dessa internacionalização passaria pela necessidade do aprofundamento da estrutura econômica mediante a subordinação da burguesia nacional às grandes empresas internacionais, em consequência, isso explica uma industrialização assimétrica às relações de poder global $^{8}$. Seguindo a lógica anterior, a transformação econômica em situações autoritárias criaria processos de deslegitimação generalizados por causa da carência do componente nacional, nessa necessidade estrutural de continuar com o dinamismo da industrialização. Em tais circunstâncias, a última fase desses regimes, em vista de suprir tais necessidades - carência do componente nacional -, seria a reincorporação seletiva e gradual de parte da burguesia nacional.

Segundo Guillermo O’Donnell, o caso brasileiro seria o tipo ideal no encaminhamento desse périplo, isto é, apesar de algumas falências em torno de algum

\footnotetext{
${ }^{7}$ Os enclaves autoritários são os dispositivos de segurança ao novo modelo político e econômico que se configurou no autoritarismo chileno. Em essência, mediante uma série de medidas protecionistas, se procurou evitar grandes transformações ao modelo no retorno à democracia.

${ }^{8}$ Para ter informação mais acabada acerca desse ponto, principalmente, da transformação econômica de Brasil: analisar o capítulo II - Ascendência Econômica do Capital Multinacional e Associado do Livro, 1964: A Conquista do Estado. Ação Política, Poder e Golpe de Classe de René Armand Dreifuss.
} 
dos indicadores que advertiriam a emergência e o rumo das transformações econômicas em tais autoritarismos. É um tipo ideal, segundo a teoria mencionada, pois a transformação econômica derivada da aliança inicial entre o Estado e Grandes Empresas Internacionais se possibilita a partir da baixa ou moderada ameaça inicial (mobilização, sindicatos e ideologias), fator chave para a composição dessa aliança e o grande capital. Porém, omite os fortes protestos no Brasil em 1967 como um elemento que pudesse alterar o pacto em menção, por outra parte, não considera as diferenças econômicas internacionais - fluxo de capitais- dos países centrais para a periferia entre a década de sessenta e setenta ${ }^{9}$, entre outros fatores que invalidam sua tese fundamental. Além disso, tais fatores que incidiriam para que alguns países se industrializem e outros se mantenham estáticos na violência e na repressão. Desse modo, pode-se indicar que os indicadores da interessante teoria dos autoritarismos burocráticos não permitem enxergar os múltiplos desdobramentos que tiveram os autoritarismos nos países da região.

Das interpretações apresentadas, a tese interpretativa da teoria de O’Donnell que se sugere, implica que noutros países não houve um processo de transformação econômica, considerando a falta de credibilidade dos juízes do capitalismo mundial como também das empresas internacionais por causa do risco de permanecer na violência estatal e sem poder aplicar a previsibilidade sobre a acumulação. Por conseguinte, nessa linha de raciocínio, seria somente possível caracterizar o caso brasileiro no processo dicotômico de internacionalização/nacionalização com uma matriz industrial em expansão, sobre esse ponto em particular, a seguinte citação ilustra parte desse processo:

Os expurgos nas Forças Armadas durante o primeiro ano tiveram uma dupla função: eliminar todo o pessoal militar que estivera estreitamente associado ao governo anterior e estabelecer predominância da ESG e da extrema direita. Foi necessário eliminar militares democratas e nacionalistas que poderiam opor-se a políticas de intensificação da repressão declarada e de favorecimento das corporações internacionais. Era necessária a rápida

\footnotetext{
${ }^{9}$ Remmer e Merkx apontam que tal indicador não toma em consideração as diferenças no sistema econômico entre a década de 60' e 70', de modo a argumentar que: 0 colapso do sistema Bretton Woods, a perdida de credibilidade do dólar, o surgimento do mercado privado de moeda e a conseguinte expansão dos prestamos aos países menos desenvolvidos são fatores que têm contribuído a esta tendência e criado importantes diferenças entre as políticas estabilizadoras dos anos sessenta e setenta. O incremento da liquides internacional também coincidiu com e, até certo ponto estimulou, a perdida de confiança na política da ISI do passado. Tais mudanças complicaram ainda mais as comparações entre alta e baixa ameaça (Remmer; Merkx, 2013, p. 171).
} 
eliminação de tais grupos das Forças Armadas. Por isso o maior número de expurgos ocorreu em $1964^{10}[\ldots]$ é também digno de nota que os maiores expurgos tenham ocorrido no Exército. A arma que mais efetivamente poderia desafiar os detentores do poder. (Alves, 2005, p. 64).

A interpretação da tese sugerida recentemente, com base nas conclusões dos trabalhos de Guillermo O’Donnell, seria desmitificada, pelo menos no caso chileno, de acordo com os trabalhos realizados pela historiadora chilena, Verónica Valdivia. A hipótese mais importante do livro da acadêmica chilena versa sobre a um golpe depois do golpe dentro do autoritarismo chileno devido a que os ideólogos do golpe de Estado chileno, dentro das Forças Armadas, ostentavam posições de cunho mais nacionalistas. No entanto, rapidamente, estas posições foram perdendo coesão e poder dentro da aliança golpista em favor da personalização de Pinochet e dos vínculos deste com o Chicago Boys:

Foram estas duas cosmovisões, estas duas formas de conceber a modernização, as que chocaram nas pessoas dos generais Leigh e Pinochet. O primeiro foi derrotado, e com ele a geração de oficiais que havia confiado o 11 de setembro de levar a cabo uma 'revolução espiritual', em mudar a mentalidade dos chilenos. Porque foram derrotados? Em grande medida porque ninguém acreditava em seu projeto corporativo: os trabalhadores os recusaram por considerá-lo um retrocesso, os empresários, pelo seu marcado estatismo e porque o Estatuto Social da Empresa e o Código do Trabalho davam, a seu juízo, ampla participação aos trabalhadores, além disso, o Estatuto foi nos primeiros anos um requisito para recuperar as empresas que a Unidade Popular Ihes havia estatizado, o qual muitos recusavam. Por outro lado, possibilitava a rearticulação da sociedade civil, particularmente dos setores populares, que foi parecendo cada vez mais atrativa para um general que caminhava lentamente a se converter na encarnação do regime e que começava compartilhar os juízos daqueles que preferiam uma sociedade mais quieta. Pouco a pouco, o anticomunismo se foi transformando em sinônimo de desmobilização e desorganização social. Ao final da década de 1970, José Piñera, Ihe ofereceria a modernização acorde a seus desejos. Por último, as próprias Forças Armadas permaneceram passivas da grande mudança: os generais que compartilhavam esse projeto foram se afastando - de forma voluntária ou não - e para 1977 ficavam poucos participantes da conjura [...] Em síntese, houve uma modernização que se sobrepus à outra: No caso aqui analisado o general Leigh e seus acompanhantes representavam um olhar acerca da tão ansiada modernização, o general Pinochet outra. O triunfo de uma delas, implicou o fim de uma etapa no pensamento das FF.AA. - O Estado Benefator - e um vagaroso caminho para outro, ao Estado Subsidiário (Valdivia, 2003, p. 201).

\footnotetext{
${ }^{10}$ Segundo a tabela colocada por Maria Helena Alves, os expurgos em 1964: Exército 505, Marinha 335 e Aeronáutica 360, entretanto, no período 1965-1967, no Exército 5, Marinha 9 e Aeronáutica 14. (Alves, 2005, p. 65)
} 
Indistintamente, tanto Brasil como o Chile iniciaram um caminho de ruptura em matéria econômica embora não se adaptassem na linha teórica esboçada por Guillermo O'Donnell. No caso chileno, por exemplo, houve uma clara tentativa de eliminar todos os elementos de caráter nacionalista -em conformidade com o plano econômico apresentado pelos Chicago Boys- radicalmente oposto com respeito ao um tipo de Estado de Bem-estar, o Estado Subsidiário. Como consequência, os mecanismos de legitimação no caso chileno não versaram na reincorporação dos elementos nacionalistas à aliança golpista, diferentemente do caso brasileiro. No Brasil, sim, houve uma clara tendência logo após a internacionalização para a ampliação das tarefas estatais na economia e sobretudo no setor produtivo mais intensivo de capital, e a expansão do Estado no Brasil teria criado a figura dos Anéis Burocráticos ${ }^{11}$, confirmando assim parcialmente a tese promovida pela teoria do autoritarismo-burocrático.

Como em qualquer outro destes regimes políticos, a principal fonte de legitimidade versa sobre os resultados econômicos. Nesse sentido, o boom econômico brasileiro sustenta parte da legitimidade de origem, "expressado na taxa de crescimento do PIB, a partir de 1968 até 1974, a que realmente foi vigorosa, cerca de 10\% ao ano" (Serra, 1979, p. 139). Concomitante, essa legitimidade de origem imbricou-se num processo de caráter político, entretanto, parte da crise se expressa em uma espécie de 'descontrole da industrialização', ou na exclusão das ofertas programáticas "que tentaram de levar a cabo uma redistribuição da renda e outras medidas do gênero" (Serra, 1979, p. 124) sustentadas, por exemplo, na eleição indireta dos presidentes da República. Desde nossa linha de pensamento, e baseado nas análises precedentes, o principal aspecto de polarização que consigna a emergência do autoritarismo brasileiro versou em evitar certas alternativas ao modelo de industrialização em andamento prévio ao golpe.

O caso chileno, na literatura de ciência política, se caracteriza como um projeto militar-autoritário voltado a reestruturação econômica de caráter revolucionário: "porque se tratou de um projeto de reestruturação global que rompe violentamente com a tradição da sociedade chilena, tanto no nível das relações econômicas como quanto à natureza do Estado, e, inclusive, as concepções ideológico-culturais

\footnotetext{
${ }^{11}$ Conceito sugerido por Fernando Henrique Cardoso no Livro Autoritarismo e Democratização, Editora Paz e Terra S/A: Rio de Janeiro, 1975.
} 
predominantes" (Vergara, 1983 p.66). Deste modo, as consequências desse projeto político vão além das políticas econômicas de um governo em particular senão também do tipo de competência política para liderar esse processo, bem como a ressignificação e a natureza em geral desse passado que se pretendeu superar.

O autoritarismo chileno se apresenta assim como um processo de oposição total com respeito ao pretérito imperfeito, à ruptura do Estado de Compromisso para um de caráter Subsidiário pode ser considerado um dos fatores mais ilustrativos daquela transição, por outra parte, no caso brasileiro, as Forças Armadas garantiram uma mínima participação aos setores contrários à aliança golpista. Numa perspectiva comparada, tais fatos evidenciam graus diferentes na profundidade da ruptura empreendida por cada país. Por outro lado, o reduzido tamanho da economia chilena fez com que "qualquer transformação destinada a assegurar o desenvolvimento capitalista devia passar pela abertura da economia ao exterior e, portanto, por uma revisão radical do 'aprofundamento' do modelo anterior" (Vergara 1983, p. 67-68).

Entre as transformações econômicas, o Estado passou de ter um papel proativo no desenvolvimento econômico ao de quase um mero fiscalizador ${ }^{12}$ e reativo das relações econômicas, em que o papel dinamizador do desenvolvimento econômico se extrapola para os agentes econômicos privados, - nacionais e internacionais-. "A liberalização extrema dos mercados, a redução do gasto e do funcionalismo público, e a privatização da maior parte das empresas em poder do Estado, inclusive as áreas consideradas estratégicas, tem significado reduzir drasticamente o tamanho e a esfera de ação estatal" (Vergara, 1983, p. 73). Assim, o eixo nodal do projeto fundacional se concebe da desestatização e privatização dos antigos ramos no qual o Estado atuava. No plano internacional, tal estratégia se sustentou na exportação de matérias primas, principalmente, as associadas aos minérios. Entretanto, no plano interno, por meio da privatização e acumulação de capital através das antigas funções estatais: fundos de

\footnotetext{
${ }^{12}$ A manifestação mais evidente da redução da importância do Estado como condutor do processo econômico a constituem a progressiva e quase total privatização das empresas estatais em poder da CORFO. Como consequência desta política, as empresas em poder da CORFO diminuíram de 480 em 1974 a 32 em 1979, vale dizer, muito menos que em 1970, quando eram 46. A fines de 1980, uma vez completado este processo, as empresas ficaram reduzidas a 15, as que se consideraram estratégicas para o desenvolvimento e a segurança nacional (Vergara, 1983, p. 73).
} 
aposentadorias, saúde, educação entre outras. Em geral, e igual que o caso brasileiro, seu principal êxito veio acompanhado do êxito econômico - revolução silenciosa ${ }^{13}$.

No caso brasileiro, a estratégia populista-nacional reformista do Governo de João Goulart, inspirava desconfiança entre atores conservadores em função do modelo de desenvolvimento proposto: A) lei de restrição às remessas de companhias multinacionais, B) maior fiscalização ao capital estrangeiro no país, C) obrigação de investir parte fundamental dos lucros no Brasil, D) monopolização estatal de áreas privadas, por exemplo, expropriação de cinco refinarias de petróleo e empresas mineiras, E) reajuste dos salários mínimos, F) Reforma Tributária baseada na taxação da renda, G) ampliação direito voto (analfabetos - soldados), H) Políticas distributivas em diversas áreas (Dreifuss, 1981, p. 131 a 134). Tais políticas eram consideradas contrárias à eficiência econômica, causando déficits fiscais e um espiral de inflação, porém para os desenvolvimentistas, era a forma de salvar um tipo de desenvolvimento económico de bases nacionais, para outros, indicadores nefastos do setor econômico brasileiro que deveriam ser erradicados do sistema político para sempre.

\section{ALGUMAS DISCUSSÕES ACERCA DO PRESIDENCIALISMO SEMISOBERANO}

A consolidação do modelo autoritário chileno é englobada no conceito de presidencialismo semisoberano pelo cientista social Carlos Huneeus, tanto em termos políticos como institucionais, enquanto, no desenho do projeto autoritário se contornam os limites ao processo decisório que se aplicaria no retorno da democracia. As fronteiras do processo político surgem da necessidade de manter o modelo de dominação no período autoritário, ao mesmo tempo, para evitar os sintomas políticos, económicos e sociais prévios ao golpe de Estado de 1973.

Nesse sentido, o conceito de presidencialismo semisoberano refere-se em limitar a autoridade das instâncias soberanas, Presidência de República e as faculdades do Congresso, mediante uma série de dispositivos políticos, legais, institucionais ou econômicos evitando possíveis cenários de ruptura com o modelo fundacional herdado. Ou seja, além das mudanças propostas no autoritarismo chileno, é possível observar

\footnotetext{
${ }^{13}$ Livro do economista Joaquin Lavín, quem, explica desde uma posição oficialista do regime miliar, as transformações econômicas e sociais no período autoritário. "Chile: Revolución Silenciosa". Zig-Zag: Santiago de Chile, 1987.
} 
também, a arquitetura de regras de jogo que delimitam tanto as fronteiras do processo decisório em uma série de pilares que asseguram o modelo. Sobre o tipo de transição no Chile, configurada a partir de um pacto entre os atores com poder do autoritarismo e a oposição política, permitida no final de dito périplo, é ilustrada como "o tipo de transição que ratificou a permanência da Constituição de 1980, inspirada no modelo de democracia protegida expressada na tutela militar sobre instituições representativas, pluralismo limitado (art. 8ํ) uma visão crítica da soberania popular" (Huneeus, 2013. P. 37). O politólogo chileno elabora várias categorias analíticas mediante as quais se enxergam as diversas dimensões nas que operam as limitações ao poder soberano, projetadas como heranças "pilares de proteção" do período autoritário chileno.

Em termos gerais, o processo de legitimação misto adotado pelo autoritarismo chileno procurou estabelecer os limites das regras do jogo democrático por meio de uma série de limitações ao poder soberano: 1- "diminuindo a autoridade do presidente, pois decisões que antes ele adotava em solitário agora deve negociá-las com outras instituições, ademais, deve ter uma maior prolixidade para impedir que suas ações sejam impugnadas ou detidas por outras autoridades" (Huneeus, 2013. P. 41). Nesse sentido, se muda a centralidade do presidente da República no processo decisório tendo que negociar e dialogar com outras instituições do Estado, por exemplo, Congresso da República, Corte Suprema, Tribunal Constitucional, entre outros. Outra área na qual o poder semisoberano se manifesta é na dimensão das políticas económicas, para Carlos Huneeus: "a política foi subordinada a economia porque se considerou que esta última tinha as ferramentas para assegurar o bem-estar e, consequentemente, a estabilidade do sistema político" (Huneeus, 2013. P. 45).

No Chile, a proteção do modelo originário se vê favorecida perante a continuidade de Augusto Pinochet numa posição de poder, dessa vez, como Comandante do Exército, ao mesmo tempo, pela criação dos senadores designados/vitalícios ${ }^{14}$. Outro dos pilares que protege a "democracia protegida" foram os altos quóruns para mudar as bases da institucionalidade do modelo, entre outros. No plano económico, as decisões tecnocráticas dominam a cena política mediante uma série de artefatos, em termos

\footnotetext{
${ }^{14}$ Mecanismos estabelecidos na constituição de 1980.
} 
gerais, a lógica da política comparada entre os dois casos em observação permite enxergar a dinâmica fundamental da estrutura fundacional no caso chileno, como evitar as mediações entre o Estado e a sociedade transferindo poder para o mercado em geral, sendo assim, se criaria um processo de despolitização generalizado como um processo que evitaria a politização no processo de políticas públicas para os próximos períodos presidenciais.

Sendo assim, o conceito de presidencialismo semisoberano é definido como os limites ao poder das instituições soberanas, na presente investigação, mediante a comparação entre a experiência autoritária chilena (1973-1990) com a experiência autoritária brasileira (1964-1985), têm como objetivo avaliar se em ambos os cenários históricos é possível enxergar processo similares, ou seja, que na etapa de restruturação económica se definam critério políticos, económicos, institucionais ou sociais projetados além do período autoritário, ou seja, como mecanismos de proteção ao modelo implementando em tais autoritarismos.

Amparado na dinâmica comparada, é possível afirmar que a experiência autoritária chilena deve ser considerada de revolucionária derivado das transformações globais em múltiplas zonas de relevância para o país, ou seja, é uma ruptura total com esse passado denominado de pretérito imperfeito. Entretanto, para a experiência autoritária brasileira, o processo de transformação para ser mais limitado que a experiência chilena, tal aspecto não implica negar a importância desse périplo, ao contrário, alude que as características singulares do processo político brasileiro levaram em conta outro tipo de necessidades históricas. Seguindo os elementos observados mediante a metodologia comparada, é possível enxergar que no Brasil, o processo de reestruturação não tinha por alvo construir uma resposta de ruptura geral enquanto as ameaças poderiam ser contornadas a través de diversos mecanismos.

Em termos gerais, esses mecanismos tiveram um componente muito mais temporal que estrutural, contudo, mecanismos ainda visíveis na dinâmica do processo político no Brasil. Sobre os elementos temporais na experiência autoritária brasileira, em- primeiro lugar, se distingue controlar pela capacidade de manobra dos presidentes, em seguida, evitar lideranças populistas assim como a possibilidade de polarizar o 
processo decisório fora dos parâmetros institucionais, ou seja, mobilizando a sociedade em geral. Apesar que o processo autoritário tenha tido um caráter mais contingencial não implica que várias das medidas tenham um efeito permanente na arquitetura institucional brasileira, fundamentalmente, por meio da contenção do estilo de desenvolvimento radical, para tais efeitos, as medidas de eliminar dissidentes ao modelo dominante no autoritarismo, evitar que reformas como a Reforma de Base proposta em seu tempo por Joao Goulart levaram um processo de modernização que dificilmente possa reviver medidas parecidas derivado do peso da modernização em curso.

As democracias nascidas das transições democráticas teriam desse modo, limites institucionais construídos justamente para evitar políticas reformistas e ou socializantes. Existem assim limitações às autoridades eleitas no período pós-autoritarismo construídas e projetadas com medidas de proteção no retorno ao processo decisório democrático. Nesse sentido, nos dos casos analisados, se enxergam uma série de medidas impostas às regras do jogo político, algumas conjunturais outras de índole estruturais, inclusive as medidas contingencias podem ter uma perspectiva permanente enquanto desarticulam elementos que posteriormente podem servir de advertência a "memória histórica", entre outras formas de expressão.

Sendo assim, as regras do jogo democrático, para os casos estudados, impõem determinadas limitações às maiorias que emergem no processo democráticos sendo processos difíceis de derrocar ou desconstruir. Os presidentes têm vastas restrições para propor uma agenda de governo, amparada no processo democrático, portanto, vertidos na expressão soberana da maioria, alguns desses processos emanam da restrição às faculdades presidenciais, outras de vetos específicos sobre determinadas áreas políticas, também do compartilhamento decisório em torno de certas matérias. Ao mesmo tempo, outras instituições ganharam territórios de poder no processo decisório, no Chile, por exemplo, o Tribunal Constitucional, muitas vezes se convertendo numa terceira câmera, o eixo dessa "nova institucionalidade" é evitar "deformar" o espírito dominante que se consolida previamente, ao mesmo tempo, freia resquícios legais que possam alterar essa dinâmica política. No caso brasileiro, tais 
dinâmicas podem ser avaliadas pelos inúmeros vetos militares no sistema político, seja na questão da verdade histórica e da memória política sobre a repressão, seja mais recentemente na verdadeira tutela exercida sobre as demais instituições políticas.

Em síntese, e contrariamente aos pressupostos de Guillermo O’Donnell, essas novas formas de dominação não levaram os países incluídos na terminologia de autoritarismos burocráticos para um lugar de desenvolvimento comum, porém, mediante a seguinte comparação é possível observar correspondências estruturais na imposição de limites ao processo soberano de cada nação com diversos graus de magnitude e profundidade.

\section{CONSIDERAÇÕES FINAIS}

O seguinte trabalho teve como objetivo fundamental refletir sobre a transformação e consolidação do autoritarismo brasileiro e chileno a partir de uma lógica comparada entre os dois objetos de estudos através do arcabouço teórico de Carlos Huneeus. O presente trabalho menção não tem como objetivo ser apenas um estudo da memória política, referente à instauração de tais regimes de governo na região, mas ao mesmo tempo, comparar e projetar as consequências globais da consolidação autoritária, tendo ademais no horizonte analítico, as implicações para o retorno à democracia.

A análise de cada uma das categorias esboçadas permitiu gerar o tratamento da informação tanto em recortes temporais específicos como em uma dimensão global, catalogada na presente investigação como a consolidação de projetos autoritários. Sobre essa dinâmica analítica, é possível observar que a ruptura condicionada pelo autoritarismo chileno é muito mais radical que no contexto brasileiro porque se refere a uma transformação de caráter global, no entanto, o caso brasileiro se desdobra em áreas consideradas críticas pela aliança golpista, cujo fim último ponderava corrigir ou restaurar certos elementos considerados desviantes, segundo a literatura politológica brasileira. Porém, a reestruturação zonal não necessariamente nega a possibilidade de projetar dispositivos de controle ou limites ao poder soberano fora do contexto autoritário.

O modelo autoritário chileno emerge de uma concatenação de transformações que em conjunto tiveram como escopo derrocar o pretérito imperfeito. No novo modelo 
organizacional se concebe e se desenham as novas regras do jogo político, ou seja, a partir desse momento se permitem certas formas de interações assim como os limites do processo decisório. Os pilares fundamentais da nova institucionalidade emergem mediante a constituição de 1980 cujos eixos orientadores emanam de: 1- a desestatização do Estado, 2- limites à decisão estratégica estatal, 3- desregulação extrema do mercado, 4- privatização de empresas estatais, 5- diversos limites ao poder soberano mediante o surgimento de uma série de imposições, 6-finalmente, é uma arquitetura que tem ademais em seus pilares institucionais a lógica de impossibilitar reeditar cenários parecidos, em suas múltiplas dimensões, ao período precedente ao golpe de Estado de 1973.

No caso brasileiro a reestruturação estava orientada inicialmente em evitar a concentração de poder presidencial fora de certos parâmetros aceitáveis, no tipo de alcance do poder presidencial assim como em medidas populares que se pudessem exercer um maior poder. Sobre o último ponto, a essência era evitar a polarização da sociedade em geral, desasa forma, evitando aumentar ainda mais o poder de ação da máxima magistratura brasileira, em consequência, é possível argumentar que era "controlar" a influência do presidente da República, o qual já era considerado como sobredimensionado, ao mesmo tempo, as possíveis medidas populares que poderiam ter inclinado ainda mais o balanço a favor dessa desproporcionalidade política. Portanto, a intervenção é considerada como o limite a figuras consideradas populistas assim como reforçar práticas políticas que incentivassem uma maior previsão capitalista, inicialmente, orientadas para empresas internacionais. Em consequência, é possível argumentar uma busca para impor limites tanto as capacidades como nos times do processo decisório evitando a conciliação entre interesses de lideranças populistas e medidas populares assim como a favor de um tipo de industrialização.

Para o caso chileno as chamadas bases da institucionalidade do modelo instauram uma "democracia protegida", por conseguinte, logo do período autoritário se transita para um processo condicionado por uma série de regras e limites institucionais fundados no medo e na coerção, em consequência, a liberdade permitida tem atuado como uma "camisa de força" que impede a deliberação de certas temáticas mediante 
diversos mecanismos que intervêm do processo decisório chileno. Os protestos chilenos do ano passado, conceituado como o Outubro de 2019, são a acumulação histórica da energia social (protestos estudantis de 2006 revolución pingüina, passeatas universitárias do ano de 2011 assim como os protestos contra a precarização da saúde pública, protestos ambientais, contra o sistema de aposentadoria privado e especulativo, entre outros) todos eles expressados em uma versão de "explosão social", ou seja, todos os problemas públicos sociais no Chile em um movimento de "protesto sistémico".

No Brasil não se observa a arquitetura institucional radical como no caso chileno, entretanto, o projeto autoritário brasileiro tinha por objetivo eliminar certos riscos para estabelecer uma espécie de modernização-conservadora. Então, a mesma emergência autoritária se transforma no principal limite ao poder soberano observando-se assim mecanismos de controle temporal e estruturais, contudo, ainda existem instancias que influenciam no processo decisório tais como a implementação de políticas estratégicas e de insulamento burocrático.

Em síntese, os regimes autoritários em estudo além de instrumentalizar uma consolidação autoritária procuram transitar além desse contexto para proteger o legado em questão. O Chile se transforma em um referente regional por aplicar as receitas neoliberais como modelo de país, nesse sentido, se observa uma ruptura total como o passado assim como a consolidação de um projeto político, econômico, jurídico e social emanado no autoritarismo e legitimado na transição. Por outra parte, o sistema brasileiro se transforma na herança regional do Estado bem feitor, porém, com uma série de transformações e limites nesse âmbito, limites que tem aparecido na transição democrática.

\section{REFERÊNCIAS BIBLIOGRÁFICAS}

Alves, M. H. (2005). Estado e Oposição no Brasil (1964-1985). São Paulo: Bauru.

Cardoso, F. H. (1975). 'Da Caracterização dos Regimes Autoritários na América Latina'. In: Collier, D. (org.), O Novo Autoritarismo na América Latina. Rio de Janeiro: Editora Paz e Terra. 
Dreifuss, R. A. (1981). 1964: A Conquista do Estado. Ação Política, Poder e Golpe de Classe. Rio de Janeiro: Vozes.

Huneeus, C. (1981). 'Elecciones No Competitivas en las Dictaduras BurocráticoAutoritarias en América Latina', Revista Española de Investigaciones Sociológicas (REIS), nำ12, p. 101-138.

(1986). 'La Dinámica de los 'Nuevos Autoritarismo': Chile en una Perspectiva Comparada', Revista de Estudios Políticos (nueva época), nำ54, Noviembre-Diciembre. - (2013). 'El Presidencialismo Semi-Soberano', Revista Uruguaya de Ciencia Política, 21(2). Montevideo, Uruguay.

O'Donnell, G. (2013). 'Relexiones sobre los Patrones de Cambio en el Estado Burocrático-Autoritario'. In: Ecos Mundiales del Golpe de Estado: Escritos sobre el 11 de Septiembre de 1973. Santiago de Chile: Ediciones Universidad Diego Portales.

Remmer, K. L.; Merks, G. W. (2013). 'El Autoritarismo Burocrático Revistado'. In: Ecos Mundiales del Golpe de Estado: Escritos sobre el 11 de Septiembre de 1973. Santiago de Chile: Ediciones Universidad Diego Portales.

Serra, J. (1979). 'Três Teses Equivocadas Relativas à Ligação entre Industrialização e Regimes Autoritários'. In: Collier, D. (org.), O Novo Autoritarismo na América Latina. Rio de Janeiro: Editora Paz e Terra.

Valdivia, V. (2003). El Golpe Después del Golpe: Leigh vs Pinochet, Chile 1960-1980. Santiago de Chile, LOM ediciones.

Valenzuela, A. (1989). El Quiebre de la Democracia en Chile. Santiago de Chile: FLACSO.

Vergara, P. (1983). 'Las Transformaciones del Estado Chileno bajo el Régimen Militar', In: Chile 1973 - 198?, Revista Mexicana de Sociología Facultad Latinoamericana de Ciencias Sociales: FLACSO. 